\title{
ARISTÓTELES E O SENTIDO POLÍTICO DA COMUNIDADE ANTE O LIBERALISMO
}

\author{
Cesar Augusto Ramos* \\ cauramos@uol.com.br
}

RESUMO O caráter comunitário da filosofia de Aristóteles resulta das diversas formas de análise da política que o filósofo apresenta na articulação dos seguintes aspectos: a tese de que o ser humano é um animal político; o modo como esta é realizada na comunidade politica, na qual o logos se manifesta como atividade discursiva compartilhada; o cultivo de determinadas virtudes ético-políticas presentes na convivência humana, sobretudo, a amizade; a autossuficiência do cidadão e o seu vínculo com a autarquia da comunidade política. A retomada de um moderno conceito de comunidade, na tentativa de reatualizar os princípios gerais do comunitarismo aristotélico, pode ser compativel com determinadas teses liberais, sobretudo a questão da liberdade (autonomia) individual e o fato do pluralismo ético e político nas sociedades modernas.

Palavras-chave Aristotelismo, comunitarismo, liberalismo.

ABSTRACT The communal nature of Aristotle's philosophy results from the various forms of analysis of the politics the philosopher shows in the articulation of the following features: the thesis that man is a political animal; the way the political community is accomplished through this thesis, in which the logos itself manifests as a shared discoursive activity; the cultivation of certain ethical and political virtues present in the human companionship, above all, friendship; citizen self-sufficiency and its relationship with the 
autarchy of the political community. In an attempt to bring up to date the general principles of Aristotelian communitarianism, the resumption of a modern concept of community can be compatible with certain liberal theses, especially the issue of individual freedom (autonomy) and the fact of the ethical and political pluralism in the modern societies.

Keywords Aristotelianism, communitarianism, liberalism.

\section{Introdução}

O pensamento de Aristóteles representa uma notável contribuição à filosofia política no que diz respeito à qualificação do homem como um ser que realiza os seus mais altos fins na relação indissociável com a comunidade (polis) na efetivação de um bem comum. Tal perspectiva orientou um modo quase programático de pensar a ação humana na matriz comunitária, repercutindo no chamado comunitarismo contemporâneo em contraste com o individualismo liberal. ${ }^{1}$ Este último concebe a comunidade como uma associação composta por indivíduos que possuem suas próprias e independentes concepções em relação a um bem comum que, eventualmente, a comunidade poderia professar como essencial para o viver humano.

Em oposição a este modo de ver a sociedade, e nela os valores éticopolíticos que orientam a ação dos indivíduos, o comunitarismo propõe uma filosofia baseada no pertencimento social. Ao ressaltar valores comunais próximos ao ideal da virtude cívica, sob o lema de que o bem deve ser correlato ao justo, pretende destacar a conformação social do sujeito engajado e imerso nas diversas configurações do viver comum. O comunitarismo aspira, assim, não só a corrigir os desvios da filosofia liberal na obliteração dos valores sociais, como também reavaliar a acusação antimodernista do comunitarismo de Aristóteles.

1 Com a publicação da "Teoria da Justiça" de Rawls, da obra de R. Nozick, "Anarchy, state and utopia" (1974) e de R. Dworkin, "Taking rights seriosly" (1977), todas elas na perspectiva da renovação do liberalismo, surge a partir da década de 1980, nos Estados Unidos da América, uma reação contra o individualismo abstrato neoliberal. Essa reação foi provocada pelas críticas de autores denominados comunitaristas. Dentre eles, destacam-se: A. Maclntyre, "After virtue" (1981); M. Sandel, "Liberalism and the limits of justice" (1982); M. Walzer, "Spheres of justice: defense of pluralism and equality" (1983); C. Taylor, "Philosophy and the human sciences: philosophycal papers" (1985) e "Sources of the self" (1990); J. Raz, "The morality of freedom" (1986). A despeito da não existência de uma unidade sistemática destes autores em torno da bandeira comunitarista - pois, eles mesmos divergem quanto ao estatuto filosófico do sentido da comunidade em suas filosofias -, o que os une, entretanto, é a crítica à insuficiência do modo liberal de tratar a importância da comunidade na formação da identidade dos sujeitos, dos direitos e das liberdades individuais, bem como as consequências que esse déficit traz à vida das pessoas e da sociedade no mundo contemporâneo. 
Alguns comunitaristas - como M. Walzer e, sobretudo, C. Taylor recusam os pressupostos epistemológicos liberais ancorados no individualismo e defendem uma política do bem comum no âmbito dos direitos como forma de melhor resguardar o pluralismo. $\mathrm{Na}$ análise de $\mathrm{C}$. Taylor, por exemplo, o comunitarismo, mesmo recusando determinadas noções vinculadas à epistemologia do individualismo liberal, não implica necessariamente a negação de certas conquistas da modernidade. O que os comunitaristas reclamam é que determinados valores sociais, incluindo a própria noção de justiça, pressupõem uma sociabilidade cooperativa do homem a partir de uma antropologia informada por razões morais, constituídas segundo uma determinada concepção de bem comunitário. Além disso, algo só pode ser repartido e distribuído, mediante princípios neutros de justiça, se tiver um significado geral, um valor de uso comum que se articula com as valorizações intersubjetivas, marcadas pela dinâmica social do mútuo reconhecimento. Com base no caráter dialógico da ação humana que se configura na perspectiva de uma comunidade de discursos expressivos, Taylor reivindica o sentido comunitário de um espaço público, no qual os direitos e os interesses individuais adquirem consistência e base para a sua defesa.

Uma linha de interpretação mais aderente ao pensamento de Aristóteles dentro do comunitarismo provém de MacIntyre, que se declara um aristotélicotomista. Criticando as tendências das filosofias morais contemporâneas que vinculam o agir moral às emoções e ao caráter do agente, ou à maximização da utilidade ou das consequências da ação, ou ao formalismo do imperativo do dever - todas essas tendências são sintomas do fracasso do relativismo utilitarista ou do universalismo do projeto iluminista -, MacIntyre procura reabilitar o conceito aristotélico de virtude como uma fonte capaz de dar conta dos desafios morais de nossa época. Este conceito, estabelecido no contexto histórico do agir humano, caracteriza-se pela indispensável dimensão comunitária, a qual se orienta por uma determinada concepção forte do bem comum, constituído pela via de uma racionalidade prática, mediante a qual todos são capazes de ordenar valores, seja na vida individual, seja na coletividade. "De acordo com essa concepção do bem comum, a identificação do meu bem, de como é melhor eu dirigir minha vida, é inseparável da identificação do bem comum da comunidade, de como é melhor para essa comunidade dirigir a sua vida" (Macintyre, 1981, p. 241).

Apesar da diversidade de suas fontes na elaboração da crítica ao atomismo liberal, os comunitaristas são simpáticos à perspectiva "neoaristotélica" na partilha de uma herança que defende o valor prioritário da comunidade. Em contraste com uma defesa restritiva do justo, segundo o valor universal 
de princípios éticos e políticos dos direitos subjetivos do liberalismo propiciando, inclusive, resistências ideológicas a uma análise alternativa mais abrangente destes direitos e da liberdade dos indivíduos -, o comunitarismo propõe a importância do bem que ele veicula na interação comunitária dos indivíduos.

A questão a ser discutida intenciona ir além da mera influência ou mesmo da presença do pensamento aristotélico - e que se mostra de modo não uniforme - na filosofia política contemporânea do comunitarismo. ${ }^{2}$ Pretendese, antes, destacar que determinados aspectos na filosofia prática de Aristóteles, e que configuram uma matriz comunitarista, podem ser reatualizados sem ferir os ganhos da modernidade, sobretudo, porque eles, na medida em que não representam a negação ou a antítese dos valores positivos do individualismo, permitem um diálogo com as conquistas hodiernas, notadamente, a liberdade individual, o pluralismo e os direitos humanos, as quais foram considerados apanágios do liberalismo. Estes aspectos são: a) o homem como animal político por natureza diante das diferentes formas da convivência comunitária e a superioridade da comunidade política; b) o logos compartilhado e as virtudes ético-políticas; c) a autossuficiência dos indivíduos e a autarquia da polis.

\section{A dimensão comunitarista da filosofia política de Aristóteles}

No que diz respeito ao primeiro aspecto, a tese aristotélica da radical sociabilidade do ser humano atesta a insuficiência de uma vida isolada: aquele que vive sem cidade ou é um ser degradado (um animal) ou está acima da humanidade (um deus), "comparável ao homem ignominiosamente tratado por Homero como 'sem família, sem lei sem lar" (Aristote, 1982, I, 2, 1253 a, 5, grifos do original). No Livro IX da "Ética a Nicômaco", o filósofo, ao analisar a virtude ética da amizade, observa que a felicidade está atrelada à

2 C. Taylor, por exemplo, busca respaldo para o seu projeto comunitarista apoiando-se na filosofia da linguagem de Herder e Wittgenstein no que concerne à definição de sujeito imerso numa comunidade linguística, na qual os significados e valores da vida estão articulados, e da qual o sujeito retira, por intermédio de relações dialógicas, tanto a sua própria identidade quanto seu posicionamento no mundo. Contudo, ao incorporar esses elementos modernos, o autor, na crítica ao individualismo liberal e à atomização das sociedades modernas, ressalta o valor da ideia de comunidade próxima ao aristotelismo (e, também, ao hegelianismo). E essa proximidade diz respeito ao sentido geral do modo como determinadas formas de sociabilidade envolvem a participação de todos na elaboração e sustentação de um sentido comum de vida política no espaço público, seja ele um "espaço comum tópico", e que aparece na conversação e na reunião de pessoas, mas, sobretudo, no "espaço comum não local 'metatópico" que é propriamente político, pois representa o compartilhamento de projetos comuns com vistas a procedimentos de cooperação (Taylor, 2000, pp. 280-281). É bem verdade que se, de um lado, Taylor está consciente de que a comunidade é parte constitutiva do indivíduo, de outro, é preciso articular a esse espírito comunitário o self individual de uma identidade moderna. 
convivência humana, ao fato do viver junto com os outros em relações de compartilhamento social, uma vez que "não menos estranho seria fazer do homem feliz um solitário, pois ninguém escolheria a posse do mundo inteiro sob a condição de viver só, já que o homem é um ser político e está em sua natureza o viver em sociedade" (Aristóteles, 1973, IX, 9, 1169 b 18/20). A polis é uma criação da natureza e que "o homem é por natureza um animal político (zoon politikon)" (Aristote, 1982, I, 2, 1253 a 2 e III, 6, 1278 b, 20).

Se o bios politikós constitui uma finalidade essencial para o homem, esta característica deve ser concebida como uma inclinação que, muito embora não seja um destino inelutável, representa um telos que porfia pela sua realização. Isto é, a tendência social (e política) da natureza humana se realiza quando o homem alcança o estatuto ontológico de um ser que vive na comunidade política (polis). Porém, esta tendência pressupõe, de algum modo, o concurso do fazer artificial (o nomos) - o campo da ação humana na criação de leis e instituições políticas que levam o homem à sua plena realização - que completa o fazer natural da physis. Por obra e arte dos homens é possível dar continuidade ao processo de realização do fim, isto é, da natureza política como destinação da vida humana. A natureza se manifesta, assim, coroada pelo concurso da ação artificial da atividade humana, não só pelo concurso da formação (paideia) para a cidadania, como também pela interveniência do legislador, cuja atuação no conhecimento do fim da polis (a felicidade de uma vida boa e virtuosa) concorre para efetivar o bios politikós. O homem é um zoon politikon por natureza, isso significa afirmar que há apenas uma pressuposição virtual da vida política. Se a consecução do fim não é arbitrária (já está dada potencialmente na origem), o seu termo final é a cidade, de tal modo que a tendência natural do homem para ser um animal comunitário deve ser atualizada, mediante o concurso da ação humana (cultura) norteada pelo logos. ${ }^{3}$

Se Aristóteles destaca o significado do processo teleológico na constituição do homem como zoon politikon, e que culmina no seu vínculo com a comunidade, qual o papel dos indivíduos na formação, organização e funcionamento desta comunidade? A posição aristotélica é a de que o Estado, embora sendo uno, não deve almejar o ideal da unidade platônica exposta na

3 Aubenque, ao sublinhar a ideia de que a natureza humana participa do processo teleológico que anima as coisas naturais, chama a atenção para o "elemento de indeterminação que introduz a liberdade humana e faz com que a natureza do homem seja uma natureza inacabada [...] que tem a necessidade da cultura para produzir seus frutos mais perfeitos. Na ordem da vida em comum, o instrumento desta cultura é o logos, a palavra trocada, e mais particularmente a deliberação (bouleusis), que permite aos cidadãos reunidos tomar, a cada vez e após um exame dos argumentos a favor e contra, a decisão mais razoável para o bem maior da comunidade. É somente por estas mediações racionais que a natureza humana pode realizar suas virtualidades mais elevadas" (Aubenque, 2004, pp. 13-14). 
"República", a despeito da tese aristotélica - de resto nitidamente platônica sobre a importância da totalidade. A crítica a Platão no Livro II da "Política" tem por base a tese de que a felicidade da polis vincula-se à felicidade individual dos cidadãos que a compõem, denunciando a desconsideração do indivíduo em prol do ideal platônico da unidade. Na medida em que as diferenças individuais são eliminadas, a comunidade política inclina-se à aspiração de uniformidade apropriada à família, tornando a vida política um ente que se assemelha a um ser individual exclusive e excludente. Obter tal identidade significa destruir o Estado, pois “é evidente que se o processo de unificação for perseguido com muito rigor não haverá mais o Estado" (Aristote, 1982, II, 1261 a, 20). A comunidade política não é apenas formada por muitos homens, mas também pela diversidade que eles apresentam, de modo a evitar a homogeneidade familiar que os semelhantes produzem. A família apresenta uma maior unidade porque nela - e muito mais no indivíduo - a tendência à identificação repele as diferenças.

Uma vez que a cidade é por natureza uma pluralidade, e se sua unificação for excessivamente compelida, de cidade ela torna-se família, e de família indivíduo: com efeito, podemos afirmar que a família é mais una que a cidade, e o indivíduo mais uno que a família. Por conseguinte, mesmo supondo que alguém tem condições de realizar esta unificação, deve-se resguardar de fazê-lo, pois isto conduziria a cidade à ruína. A cidade é composta não apenas de uma pluralidade de indivíduos, mas ainda de elementos especificamente distintos (Aristote, 1982, II, 2, 1261 a, 15-25).

Entretanto, esta análise não autoriza pensar a polis segundo o modelo do arranjo atomístico de indivíduos dispersos. Os membros da polis devem constituir uma organização política de cidadãos livres e iguais que guardam um sentido de pertencimento comunitário. Se a polis não constitui uma unidade indistinta, e nem é um agregado social que reúne indivíduos sob a forma de uma simples aglomeração, ela deve retratar o ideal político de uma comunidade que possui o caráter da identidade de uma formação comunitária plena, e que tem prioridade em relação às partes que compõem o todo social. Porém, este ideal não deve, de forma alguma, estimular a nulidade do indivíduo, absorvendo-o na unidade indiferenciada da comunidade política. Mesmo como partes do todo, os indivíduos devem diferir, pois a identidade da polis permite e até exige indivíduos diferenciados, só possível pela diversidade. ${ }^{4}$ Ao recomendar o caráter plural da cidade, Aristóteles entende

4 Segundo Barker, numa linguagem que ecoa o hegelianismo, "na lógica, como na política, apenas um universal concreto, o qual reconhece e dá aos seus membros individuais seu pleno significado pode ter alguma possibilidade de ser verdadeiro" (Barker, 1978, p. 404). Barker conclui que Aristóteles "não estava 
que a existência de cidadãos que diferem em suas distintas capacidades na execução de tarefas, mediante a cooperação, torna-se indispensável para o cumprimento da diversidade de fins que são próprios à comunidade política. Num Estado onde a multiplicidade está garantida, a igualdade não possui o sentido de uma uniformidade irrestrita. Sendo iguais em parte e desiguais em outros aspectos, o princípio que rege as relações interindividuais é o da reciprocidade proporcional.

Em relação ao segundo aspecto comunitarista da filosofia política de Aristóteles, ou seja, o logos compartilhado e as virtudes ético-políticas, é preciso ressaltar que o homem não é um simples animal gregário, portador de uma espécie de "sociabilidade" que ele partilha com outras espécies, também solidárias, como as abelhas e as formigas. A afirmação de que o homem é por natureza um animal político retrata a ideia de que ele é o único ser que possui a capacidade discursiva, e que é capaz de fazer da linguagem um uso compartilhado com outros homens para estabelecer fins comuns.

Que o homem seja um animal político no mais alto grau do que uma abelha ou qualquer outro animal vivendo num estado gregário, isso é evidente. A natureza, conforme dizemos, não faz nada em vão, e só o homem dentre todos os animais possui a palavra. Assim, enquanto a voz serve apenas para indicar prazer ou sofrimento, e nesse sentido pertence igualmente aos outros animais [...] o discurso serve para exprimir o útil e o prejudicial e, por conseguinte, também o justo e o injusto; pois é próprio do homem perante os outros animais possuir o caráter de ser o único a ter o sentimento do bem e do mal, do justo e o injusto e de outras noções morais, e é a comunidade destes sentimentos que produz a família e a cidade (Aristote, 1982, I, 2 , 1253 a, 7-12).

O discurso só é possível pela mediação do homem como ser político, e a maneira mais adequada para analisar a dimensão do logos discursivo é, propriamente, uma forma específica de conhecimento político, o qual é definido como a ciência suprema ou arquitetônica por excelência, pois ela "utiliza as demais ciências e, por outro lado, legisla sobre o que devemos e o que não devemos fazer" (Aristóteles, 1973, I, 1, 1094 b, 5).

O estudo da política não possui um fim em si mesmo, não tem por objeto as coisas necessárias e eternas, e nem visa apresentar um conhecimento axiomático e metafisicamente normativo. Destarte, o estagirita concede à política um estatuto epistemológico peculiar - aquele que tem por objeto a

de fato atacando a unidade como o fim do Estado, mas uma falsa unidade [...] A unidade indiferenciada pertence a uma escala mais baixa da evolução. A unidade heterogênea à mais alta escala [...]" (ibidem, p. 404). 
praxis na classificação proposta por Aristóteles sobre as ciências. Esta forma de saber não visa à posse de um conhecimento ideal submetido ao rigor de um saber contemplativo, mas aquele que concerne à contingência das ações humanas enraizadas na vida da comunidade. A política (bem como o seu conhecimento) tem por finalidade esclarecer o sentido destas ações, segundo o critério da boa razoabilidade fornecida pela sabedoria prática (phronesis) e pela experiência da repetição dos casos e das situações particulares. $\mathrm{Na}$ medida em que a política é um conhecimento deste tipo, ela se distancia do modelo abstrato das essências universais. Ao retratar a atividade adequada ao modo próprio de atuação (praxis) que se dá na polis e pela polis, a política se constitui em instrumento essencial para se alcançar a eudaimonia, possível apenas no seio da comunidade.

As atividades humanas constitutivas do bios politikós eram a ação (praxis) e o discurso (logos). Quem vive na polis deve possuir a disposição discursiva do $\operatorname{logos}$, do homem (cidadão) que fala e discorre pela palavra como instrumento de persuasão que se dirige a outrem em pé de igualdade, com o objetivo de buscar um entendimento geral no espaço público da ágora e da ekklesía. Entre iguais, a disputa (polemos) ocorre pelo diálogo, pelo convencimento por meio do discurso como forma superior do relacionamento entre os cidadãos. $\mathrm{O}$ modo político de decidir exclui a violência, pois o convencimento pela palavra é feito por argumentos produzidos por uma razão dialógica.

Para os gregos [observa Arendt] forçar alguém mediante violência, ordenar ao invés de persuadir, eram modos pré-políticos de lidar com as pessoas, típicos da vida fora da polis característicos do lar e da vida em família, na qual o chefe da casa imperava com poderes incontestes e despóticos, ou da vida nos impérios bárbaros da Ásia, cujo despotismo era frequentemente comparado à organização familiar (Arendt, 1981, pp. 35-36).

Em sintonia com esse logos compartilhado, os homens atualizam a dimensão do viver junto numa forma de sociabilidade comunitária, mediante um relacionamento conveniente a esse viver com base na justiça e na amizade, as quais, por isso mesmo, constituem virtudes ético-políticas. ${ }^{5}$

5 No comentário de Aubenque, "é pelo fato de possuir a linguagem que o homem tem a percepção das noções morais e, possuindo os homens esta percepção em comum com outros homens, eles constituem com estes uma comunidade, seja familiar, seja política" (Aubenque, 2004, p. 7). Aubenque chama a atenção para a importância do pertencimento comunitário pela mediação da capacidade de comunicação, inexistente para um indivíduo absolutamente autossuficiente que, como um deus, não tem necessidade dos outros. "Não pode fazer parte de uma comunidade um indivíduo incapaz de 'comunicar' (koinonein). A pertença à comunidade implica, da parte do indivíduo, a vontade e a capacidade de comunicar, de 
Por fim, no que diz respeito ao terceiro aspecto, a saber, a autossuficiência dos indivíduos e autarquia da polis, o filósofo, no livro VII da "Política", discute a questão se o bem supremo que a cidade deve realizar é o mesmo para o indivíduo, observando que "temos que nos pôr de acordo sobre o modo de vida o mais digno de ser escolhido para todos por assim dizer e, depois, ver se este modo de vida é o mesmo para a comunidade e para o indivíduo tomado isoladamente, ou se ele é diferente" (Aristote, 1982, VII, 1, 1323 a, 17-20). Ou seja, trata-se de saber em que consiste para todos uma vida que se apresenta como a mais predileta, para avaliar se aquela que o indivíduo escolhe para si coincide ou não com a vida que ele leva na comunidade.

Aristóteles não titubeia em afirmar que é possível realizar uma vida mais perfeita, que vale tanto para o indivíduo como para a comunidade. "Vêse, assim, claramente que a vida mais perfeita deve necessariamente ser a mesma, tanto para cada indivíduo em particular como para os Estados e os homens tomados coletivamente" (Aristote, 1982, VII, 3, 1325 b, 30). Se é plausível sustentar a tese de que a felicidade do indivíduo e da cidade não se opõem, é porque para ambos a autossuficiência (autarquia de bens e de caráter) é fundamental, tanto para a consecução do fim comunitário como dos fins individuais.

A convergência ou o paralelismo entre ser livre e ser cidadão é evidente para Aristóteles, pois, a polis é uma "comunidade de homens livres" (Aristote, 1982, III, 6, 1279 a, 21). Isso porque, o homem não só tem em si mesmo a finalidade do seu agir, como também, na condição de cidadão, não está submetido ao domínio de outrem, nem a constrangimentos ou impedimentos externos que impendem o exercício de uma vida feliz e virtuosa. Se a felicidade do homem inclui a noção de realização de fins no cumprimento de sua natureza, então, esse fim inclui a dimensão da autossuficiência, e o seu pleno desenvolvimento requer bens comunitariamente compartilhados em consonância com a autarquia da comunidade. Nessa medida, não constitui uma exorbitância ética e política afirmar que a felicidade da cidade e a do indivíduo podem coincidir, e que a melhor constituição é aquela que assegura aos cidadãos a melhor vida com base no critério da autossuficiência para os indivíduos e da medida maior da autarquia para a comunidade.

É bem verdade que, no contexto cultural e ideológico da antiga Grécia, a autossuficiência exigia o afastamento de entraves ou de dependências que

compartir, de partilhar, de participar" (ibidem, p. 7). Alguns comentadores chegam a dizer que "o conceito de koinonia politiké elaborado por Aristóteles é o primeiro modelo da livre ação comunicacional - para utilizar a terminologia de Habermas - que se apresenta na história das ideias" (Guariglia, 1979, p. 41). 
impediam a sua consecução. Apenas os cidadãos livres das ocupações servis não estavam compelidos a proverem suas necessidades cotidianas, permitindo que se dedicassem à política. ${ }^{6}$ Os membros da polis são os cidadãos (politai) livres, desobrigados da servidão do trabalho da vida, da necessidade, e esta condição não pode ser atribuída aos escravos e aos trabalhadores, cuja ocupação laboral lhes retira toda possibilidade da cidadania e, até mesmo, do exercício de uma vida virtuosa com base no ócio e na contemplação. O conceito de virtude não se aplica a qualquer homem livre, mas apenas àqueles que "não estão submetidos aos trabalhos indispensáveis à existência" (Aristote, 1982, III, 5,1278 a, 10). ${ }^{7}$

Para os gregos, no momento em que a identidade do indivíduo se afirmava na comunidade política, os interesses individuais estavam alinhados com o bem comum, e não tinham o significado de direitos individuais, pois a instância privada não era digna de atenção para se postular a sua autonomia, estabelecendo uma relação dicotômica entre o indivíduo (privado) e o Estado (público), tal como os modernos a concebem. Se o homem se realiza na e pela polis, a cidade só efetiva essa finalidade se ela permitir e estimular ações morais, e se os indivíduos forem moralmente educados para nela viverem.

Quando cidadãos de uma cidade ideal comparecem à assembleia e decidem como votar, eles o fazem não com o objetivo de representar suas famílias, clãs ou qualquer outro partido. Eles vêm como indivíduos para avaliar a força de argumentos competentes, não como partidários de uma subcomunidade que procuram proteger ou ampliar seu quinhão. Como cidadãos, o objetivo não é favorecer algum setor, mas sempre promover o bem da comunidade como um todo (Kraut, 2002, p. 353).

Mais do que instrumento para a proteção dos indivíduos pela mediação do Estado que detém a autoridade e que assegura as trocas mercantis e pune os crimes, a comunidade política é uma força moral para a consecução de uma vida feliz, uma vez que "a cidade não é uma simples comunidade de lugar, estabelecida com vistas a impedir as injustiças recíprocas e favorecer

6 Aristóteles admite que o estatuto de cidadão varia conforme o tipo de constituição da polis. Na democracia, são cidadãos aqueles que têm o direito de participar ativamente de uma função pública, do governo, da justiça, ou da assembleia, uma vez que essa forma de governo se caracteriza pelo governar por turnos. Numa constituição aristocrática, em que o critério é o mérito (virtude), os trabalhadores, não tendo oportunidade nem tempo para exercitar atividades dignas da vida virtuosa, não são admitidos como cidadãos. Na oligarquia é possível aceitar o artesão como cidadão, uma vez que o critério, nessa constituição, é a riqueza.

7 Arendt afirma que a liberdade entre os gregos só podia ser política, isto é, um fato da polis, contraposta à necessidade que é fenômeno "pré-político", próprio da vida privada, da família, na qual é possível o monopólio da força, da violência, da subjugação. "Todo conceito de domínio e de submissão, de governo e de poder no sentido em que o concebemos, bem como a ordem regulamentada que os acompanha, eram tidos como pré-políticos, pertencentes à esfera privada, e não à esfera pública" (Arendt, 1981, p. 41) . 
as trocas" (Aristote, 1982, III, 9, 1280 b, 30). Ela é uma comunidade moral e política que se organiza não apenas com o objetivo de proteger e manter a vida - esta finalidade representa apenas um meio para a realização do fim superior boa vida -, mas, também, promover o bem viver de homens bons, amigos e justos.

$\mathrm{Na}$ medida em que o cidadão deixa de participar direta e ativamente do poder, a moderna concepção de liberdade, marcada pelo individualismo, pelo gozo pacífico da independência privada, não tem lugar no mundo político grego. Não havia, então, direitos individuais privados, mas o dever do cidadão de colaborar para a realização do bem comum da comunidade. No Estado grego, que desconhecia o sistema de representação política, a liberdade era compatível com a submissão do indivíduo à autoridade pública, uma vez que a cidadania não era definida como prerrogativa do indivíduo para reivindicar, defender ou postular os seus direitos subjetivos e de não estar submetido à autoridade de outrem senão por força da lei.

Em síntese, são estes os aspectos (o homem como animal político por natureza diante das diferentes formas da convivência comunitária e a superioridade da comunidade política; o logos compartilhado e as virtudes ético-políticas e a autossuficiência dos indivíduos bem como a autarquia da polis) que, articulados, conferem à filosofia prática de Aristóteles o epíteto de comunitarista.

\section{A atualização do comunitarismo aristotélico ante o liberalismo}

Se assim é, em que medida este comunitarismo - na linha de uma filosofia ético-política que concebe a prioridade do bem (no sentido de uma vida feliz e bem- sucedida) sobre o justo (da prevalência de regras universais regidas por princípios procedimentais) - pode ser, definitivamente, considerado antiquado, de tal maneira que a filosofia política aristotélica não mais permite sustentar teses que poderiam embasar alguma forma de conciliação com o liberalismo, sobretudo, no que diz respeito à autonomia do indivíduo e aos direitos humanos?

Uma linha de interpretação, que destaca de forma seminal a inadequação do pensamento político de Aristóteles com a modernidade, provém de B. Constant, cuja análise comparativa entre a liberdade dos antigos e a dos modernos tornou-se paradigmática. "A liberdade individual constitui a verdadeira liberdade moderna” (Constant, 1980, p. 509), sublinha o liberalismo de Constant no diagnóstico que ele faz das vantagens da liberdade dos modernos. A liberdade individual representa uma necessidade moderna 
porque supõe a livre disponibilidade do indivíduo em relação aos vínculos comunitários, e a liberdade política não é outra coisa senão a garantia desta liberdade. Para os antigos, na visão de Constant, quanto mais presença e participação nos assuntos públicos, mais livres os indivíduos eram, daí a necessidade de uma vida política com participação direta. Para os modernos, a ausência dos assuntos públicos determina um alcance mais amplo para as questões privadas e, portanto, maior fortalecimento da representação política dos direitos individuais. $O$ exercício da política, mediante um governo representativo, permite a existência de um espaço livre e intocável para a realização dos interesses privados.

O princípio que informa a cultura do individualismo liberal realça a concepção de que cada indivíduo, no uso de sua liberdade, pode escolher o bem que julga ser o melhor para si na sua utilidade ou conveniência. $\mathrm{O}$ valor da individualidade se traduz, assim, no livre exercício da vida privada e que exige a liberdade para a sua fruição e o consequente direito a ela. $\mathrm{O}$ liberalismo difunde a ideia de que o indivíduo é, portanto, juiz dos seus fins, interesses e ações, e a esfera pública deve assegurar essa prerrogativa como uma necessidade moral e jurídica.

$\mathrm{Na}$ medida em que a sociedade tem que ser neutra no tocante à questão da boa vida e da felicidade dos seus membros, limitando-se ao compromisso procedimental de tratar as pessoas com igual respeito segundo a regra básica da prioridade do justo, o liberalismo defende a pluralidade das concepções de bem, caracterizada pela existência de diversas doutrinas morais, filosóficas e religiosas, e cujo reconhecimento moral e jurídico é essencial para resguardar a liberdade e o interesse de cada indivíduo na sociedade. Por isso, o liberalismo se reporta aos direitos (subjetivos), definidos numa esfera prépolítica, sobretudo, a liberdade (negativa), mediante a qual cada um pode seguir da maneira que mais lhe convém uma determinada concepção de bem, a qual pode, a qualquer momento, ser revisada sem nenhum impedimento de terceiros, inclusive do próprio Estado. Os direitos representam uma garantia contra toda e qualquer forma de sacrifício ou barganha em relação ao Estado, que tem por missão protegê-los, uma vez que foi constituído para esse fim, mediante um acordo (contrato) coletivo legítimo.

Assim, qualquer concepção mais forte ou densa de comunidade - como a aristotélica - é inadequada às teses do moderno individualismo, sobretudo, a necessidade da liberdade (autonomia) individual para a realização da diversidade de fins e interesses dos sujeitos. Por conseguinte, constitui um ponto fundamental na formulação do liberalismo político o reconhecimento teórico e histórico do pluralismo nas sociedades democráticas modernas. Para 
a realização desses princípios, faz-se necessário o abandono do ideal ético e político abrangente de comunidade, a qual deve se reger apenas por uma teoria da justiça circunscrita à estrutura de base das sociedades democráticas liberais modernas. É o que dispõe o liberalismo político de J. Rawls.

A teoria da justiça como equidade ao não se fundamentar numa doutrina exaustiva moral, religiosa ou filosófica, abandona o ideal de comunidade política e considera a sociedade como um conjunto de associações ou de indivíduos distintos que só cooperam para alcançar sua própria vantagem pessoal ou associativa sem compartilhar nenhum fim último (Rawls, 2008, p. 54).

Contudo, a relação da filosofia prática de Aristóteles com o liberalismo não se limita a um confronto que resulta em desdém das teses filosóficas do primeiro, sobretudo, aquelas do âmbito da política, por considerá-las inadequadas ao moderno individualismo. Uma outra linha de interpretação procura evitar a relação dicotômica entre o caráter comunitarista de Aristóteles - se bem avaliado - e os valores importantes da modernidade, mormente, aqueles veiculados e defendidos pelo liberalismo, como, por exemplo, a liberdade e os direitos individuais.

Höffe perfila entre aqueles que não veem incompatibilidade entre a filosofia prática de Aristóteles e a filosofia política do liberalismo moderno. ${ }^{8}$ Este autor procura uma posição de conciliação entre o comunitarismo de Aristóteles (que se exprime na ideia do bem) e o individualismo liberal (que se manifesta na ideia do justo), chamando a atenção para a presença de aspectos conceituais na filosofia prática aristotélica que não se opõem às teses de um "liberalismo autêntico", ${ }^{9}$ com exceção daqueles aspectos que não se identificam com a época moderna no que diz respeito aos princípios universais da dignidade da pessoa e aos seus direitos. Na interpretação de Höffe, Aristóteles não promove o confronto entre o justo e o bem, mas apresenta a alternativa conciliadora de que a vida feliz e boa caracteriza-se por aquilo que é, também, justo. Ao contrário do que se lhe atribui hoje, Aristóteles representa

8 Alguns intérpretes querem, até mesmo, remontar a Aristóteles a presença de teses reconhecidamente liberais (Cf. Miller, 2001).

9 Esse liberalismo autêntico é caracterizado por Höffe pelos cinco elementos seguintes: "1. A coexistência dos homens está sujeita a regras coercitivas de que o direito, gramática (parcial) da sociedade, apresenta a totalidade. 2. O direito não está sujeito a regras arbitrárias, mas a regras que merecem ser reconhecidas por todas as partes [...] 3. Tanto a determinação imediata do direito (universalista) como a sua execução, e sobretudo a decisão autoritária nos casos litigiosos, não resulta de opiniões privadas e do poder privado, mas dos poderes públicos. 4. Já legitimação destes últimos resulta em última instância do acordo de todos os interessados; por outras palavras, todo o poder procede do povo. 5. Devido já às tarefas diferenciadas, mas em seguida, também, com o fim de impedir todos os abusos de poder, os poderes públicos estão divididos e sujeitos a um mútuo controle" (Höffe, 2001, p. 172). 
não uma alternativa ao liberalismo, mas a consolidação desse último: em vez de uma prioridade do bem sobre o justo, a sua identidade. O bem de uma comunidade-sociedade reside no reconhecimento de princípios comuns do justo e do injusto [...] Em suma, aquele que lê Aristóteles não encontra nele o antepassado do comunitarismo, o qual se compreende como alternativa ao liberalismo e ao universalismo, mas os traços fundamentais da forma de filosofia política e de filosofia social que hoje é necessária, a saber, um universalismo liberal, que vai até aliar à compreensão e ao direito a necessidade de pertenças particulares (Höffe, 2001, pp. 176-177).

\section{Uma outra tendência interpretativa na recepção do pensamento político de} Aristóteles procura realçar aquilo que lhe é peculiar e auspicioso: a dimensão comunitária, sobretudo, no que diz respeito à atualização dos aspectos anteriormente já analisados, e que estimulam revisitar este pensamento. Esta outra perspectiva de análise é possível a partir da recepção crítica da filosofia prática aristotélica. ${ }^{10} \mathrm{Com}$ efeito, a tese comunitarista de Aristóteles - formulada no princípio de que as pessoas precisam e desenvolvem um sentido ético-político de pertencimento e de integração em uma forma social mais abrangente, e que estabelece fins comuns, propósitos compartilhados, práticas cooperativas - subsiste com os valores que são atribuídos ao homem na particularidade da sua vida e da sua atuação como indivíduo livre. A rigor, o indivíduo não pode ser pensado de forma isolada, e o seu significado como ser comunitário deve ser visto como um atributo moral e político importante para a sua independência como cidadão, capaz de discutir, avaliar e julgar bem em prol da comunidade com um todo, e não na consideração de razões partidárias utilitaristas ou do espírito individualista de secessão. ${ }^{11}$

10 É viável apreciar a pertinência da filosofia prática a partir de uma perspectiva neoaristotélica, sobretudo, na teoria ético-política. O termo neoaristotelismo foi utilizado pela primeira vez, no contexto alemão, por Habermas e Apel no debate sobre a interpretação aristotélica feita por Gadamer e seus discípulos, considerada conservadora. O IX Congresso Alemão de Filosofia (1969) tematiza a necessidade de uma retomada da filosofia prática, estimulando interpretações diferentes da filosofia prática aristotélica por autores como K.-O. Apel, J. Habermas, M. Riedel, F. Kambartel e outros (cf. Riedel, 1972-1974). O neoaristotelismo de autores como $\mathrm{H}$. Arendt - esta última também influenciada por Heidegger, a partir de seus cursos sobre Aristóteles realizados em Friburgo, no período de 1919-1923, e em Marburgo, no período de 1923-1928 -, J. Ritter, P. Aubenque, E. Anscombe, A. Maclntyre, B. Williams, A. Sen, H. Jonas, E. Berti e outros pretende fornecer uma livre interpretação do pensamento de Aristóteles visando adaptálo aos problemas e à situação da vida contemporânea. Com efeito, como observa Berti, "frequentemente, ainda hoje - e não por acaso é assim há dois mil anos -, a leitura de uma página de Aristóteles faz pensar, faz refletir, faz meditar, ensina algo acerca do sentido de certas realidades, algo diferente do que se pode aprender pelas obras de ciência ou de literatura, ou ainda de poesia" (Berti, 1997, p. 326).

11 Ainda que atribuindo à filosofia política de Aristóteles um caráter eminentemente comunitarista e que se opõe claramente ao formalismo e ao procedimentalismo dos modernos, Aubenque defende a tese de que o logos aristotélico, ao se realizar na comunidade pela deliberação em comum, se pluraliza pela presença das diversas formas de vida sem, contudo, cair no relativismo e no artificialismo. "A polis [conclui Aubenque] não é uma agregação artificial de indivíduos naturalmente solitários, que somente, acederiam à vida política por um contrato, em que cada um só alienaria sua independência sob a condição da representação de uma utilidade mais elevada: logo, Aristóteles não é liberal no sentido da modernidade. 
A questão básica para Aristóteles não diz respeito à demanda, de resto moderna, da representação política de interesses privados; mas em saber qual é a melhor forma de vida, a mais adequada para o homem não só na sua singularidade como, também, para os outros. A diversidade da convivência comunitária que o cidadão constitui para si e para os seus semelhantes, com vistas à realização de diferentes objetivos que cada comunidade propicia para o bem viver e para a felicidade, encontra na forma de vida política o modo supremo desta convivência. O vínculo orgânico que o indivíduo mantém com a comunidade política, mediante a qual ele pode orientar a sua ação por um conjunto de valores éticos e políticos, qualificados de virtudes comunitárias, permite a realização da sua felicidade na convivência com os outros. Assim, a sabedoria prática, a justiça e, sobretudo, a amizade, são virtudes morais que adquirem um sentido nitidamente comunitário, pois envolvem a convivência humana no seu aspecto mais profundo na constituição de objetivos comuns. Do ponto de vista político, um cidadão moralmente virtuoso deve realizar, junto com os outros, a finalidade maior da comunidade: a busca de uma vida autossuficiente, permeada pelo ideal ético das virtudes. ${ }^{12}$

\section{Conclusão}

A análise que o estagirita propõe é, portanto, significativa para se compreender a relação do indivíduo com a comunidade e constitui, ainda hoje, estímulo teórico importante para a reflexão comunitarista e, também, liberal. Assim, a tese aristotélica da condição comunitária do homem não demonstra ser incompatível com a atualização de um tipo de comunitarismo que não

Não é a solidão (como em Rousseau), mas é a participação na comunidade que é para ele "natural" (Aubenque, 2004, pp. 8-9).

12 Embora seja verdade que a ética parece se inclinar mais para um ideal de felicidade pessoal, contemplativo e intelectualista, a política volta-se para uma forma de realização comunitária (o supremo bem humano), inseparável da virtude, pois a felicidade não é o fim do homem só, isolado, mas do cidadão. F. Wolff, no comentário sobre a relação entre a ética e a política, observa que "a conduta dos indivíduos constitui a matéria-prima da ética, e a história das cidades com seus regimes constitui o da política. De uma para outra, há múltiplos laços, com sentido duplo: a política continua sendo, para Aristóteles - é ao menos o que ele afirma no início de sua Ética -, a suprema ciência, da qual dependem o estudo e a efetivação do 'soberano bem'; o homem só pode realizar sua natureza de homem na e pela cidade. Inversamente, a cidade, quando digna desse nome, tem uma finalidade altamente moral, como Aristóteles não para de repetir na Política. Além do mais, a conduta individual somente poderia ser boa em geral com o auxílio das leis da cidade, que mostram permanentemente qual é a regra e dispõe de um poder coercitivo quando falta virtude; reciprocamente, são necessários muitos legisladores virtuosos para dar boas leis à cidade. A ética, portanto, não é independente da política. E a política depende da ética em seu direcionamento quanto em seus meios" (Wolff, 1999, p. 20). 
exclui os valores da modernidade, como a liberdade individual e o pluralismo, e que foram considerados apanágios ideológicos do liberalismo. ${ }^{13}$

Com base na hipótese de que a contribuição da filosofia prática de Aristóteles é plausível na reavaliação de um moderno comunitarismo, é possível afirmar que o caráter comunitário da sua filosofia assume a condição de um elemento teórico indispensável ao articular as diversas formas de análise da política que o filósofo apresenta; seja na tese de que o ser humano é um animal político; seja no modo como essa tese se realiza nas diferentes formas da vida comunitária, culminando na superioridade da forma política, na qual o logos se manifesta como atividade discursiva compartilhada; seja pelo cultivo de determinadas virtudes ético-políticas presentes na convivência humana. Estes aspectos, nitidamente comunitaristas, acabam determinando a posição e o bem do indivíduo em relação à comunidade, definindo com propriedade a articulação de duas faces na constituição da política: a liberdade individual e a autarquia comunitária, o bem desta última e o bem dos indivíduos. Sem a presença da face da liberdade, a dimensão comunitária pode oscilar para uma abstração vazia ou evoluir para uma ordem totalitária; e, sem o viver junto, o indivíduo simplesmente não pode compreender e realizar aquilo que é valioso para si mesmo - a liberdade e a felicidade como bens propriamente individuais.

Uma retomada moderna do conceito de comunidade, com base nos princípios gerais do comunitarismo aristotélico, não se revela necessariamente anacrônica. Ao contrário, ela pode, inclusive, ser compatível com determinadas teses liberais modernas, sobretudo, a questão da liberdade (autonomia) individual e a existência do pluralismo ético e político. O apego comum a valores comunitários, e que requer a participação do cidadão na perspectiva do republicanismo, pode representar um aspecto importante para a defesa dos direitos do indivíduo.

O gênio de Aristóteles ecoa, assim, através dos séculos alcançando o comunitarismo contemporâneo, na medida em que este procura, juntamente com o ideal republicano da virtude cívica, ressaltar valores comunais, os quais - sob o lema de que o bem deve estar articulado com o justo - estimulam a possibilidade de conexão com o significado normativo do ideal dos direitos subjetivos, sobretudo, a liberdade e a igualdade. Destarte, é possível

13 Ao lado do significado moral e sociológico, o sentido político de comunidade é descrito por Honneth como aquele conceito que "serve hoje, na maioria das vezes, para enfatizar as formas de participação comunitárias, que devem figurar como condições necessárias de uma democracia viva. Considera-se que as chances de tal participação são maiores se os sujeitos puderem saber-se ativamente ligados a um objetivo comum. Aqui o conceito de 'comunidade' é, portanto, utilizado para mostrar, no espírito do pragmatismo americano, que quanto mais forte for o apego comum aos valores, tanto mais ativa será a participação" (Honneth, 2003, p. 292). 
afirmar que a reflexão ética e política de Aristóteles, ao compreender a ação humana norteada pela ideia do bem comum e por práticas e fins públicos ou comunitários, permite um diálogo com a perspectiva liberal de ênfase aos fins individuais ou particulares, os quais encontram um solo mais seguro de realização quando estão comunitariamente assegurados.

\section{Referências}

ARENDT, H. "A condição humana". Tradução de Roberto Raposo. São Paulo: Forente; Salamandra; Edusp, 1981.

ARISTÓTELES. "Ética a Nicômaco". Tradução de Leonel Valandro e Gerd Bornheim. São Paulo: Abril Cultural, 1973. Vol. IV: Os Pensadores.

ARISTOTE. "La politique". Tradução de J. Tricot. Paris: Vrin, 1982.

ARISTOTLE. "The works of Aristotle translated into english". Ed. by W. D. Ross. Oxford: Clarendon Press, 1966.

AUBENQUE, P. “Aristóteles era comunitarista?” Dissertatio, pp. 19-20, 2004.

AVINERI, S., DE-SHALIT, A. (ed.). "Communitarianism and individualism". Oxford: Clarendon Press, 1992.

BARKER, E. "Teoria política grega". Tradução de Sergio Bath. Brasília: Ed. Universidade de Brasília, 1978.

BERTI, E. "Aristóteles no século XX (Aristotele nel Novecento)". Tradução de Dion Davi Macedo. São Paulo: Loyola, 1997.

CONSTANT, B. "De la Liberté chez les modernes". Paris: Librairie Générale Française, 1980.

GUARIGLIA, O. "Dominación y legitimación en la teoria política de Aristóteles". Revista Latinoamericana de Filosofia, Vol. V, Nr. 1, Mar. 1979.

HÖFFE, O. “Aristóteles”. In: História da filosofia política 1. A liberdade dos antigos. Dir. A. Renaut. Tradução de Elsa Pereira. Lisboa: Instituto Piaget, 2001.

HONNETH, A. "Comunidade". In: Dicionário de ética e filosofia moral. Org. M. Canto-Sperber. São Leopoldo: Ed. Unisinos, 2003.

KRAUT, R. “Aristote. Political philosophy”. Oxford: Oxford University Press, 2002. MACINTYRE, A. "After virtue: a study in moral theory”. London: Duckworth, 1981. MILLER, F. "Nature, justice and rights in Aristotle's Politics". Oxford: Oxford University Press, 2001.

RAWLS, J. "La priorité du juste et les conceptions du bien". Archives de Philosophie du Droit, 54, 2008.

RIEDEL, M. "Rehabilitierung der praktischen Philosophie". 2 Vol. Friburgo: Rombach, 1972-1974.

TAYLOR, C. “Argumentos filosóficos”. Tradução de Adail U. Sobral. São Paulo: Edições Loyola, 2000.

WOLFF, F. "Aristóteles e a política”. Tradução de Thereza Stummer e Lygia Watanabe. São Paulo: Discurso Editorial, 1999. 